\title{
Seasonality of internal gravity waves kinetic energy spectra in the Ligurian Basin
}

\section{Variations saisonnières des spectres d'énergie cinétique d'ondes internes de gravité en mer Ligure}

\author{
Hans van Haren ${ }^{\mathrm{a}, *}$, Claude Millot ${ }^{\mathrm{b}}$ \\ ${ }^{a}$ Netherlands Institute for Sea Research (NIOZ), P.O. Box 59, 1790 AB Den Burg, The Netherlands \\ ${ }^{b}$ Antenne LOB-COM-CNRS, c/o Ifremer, BP 330, 83507 La Seyne-sur-mer, France
}

Received 28 February 2003; revised and accepted 16 June 2003

\begin{abstract}
In the central Ligurian Basin, Western Mediterranean Sea, dense water formation occurs in winter so that near-surface stratification displays a marked seasonality. Consequently, kinetic energy spectra from the surface to intermediate depths are entirely different in summer and winter. In summer, the spectra show a peak near the local inertial frequency $(f)$. The polarization of currents in the internal gravity wave frequency $(\sigma)$ band $(f<\sigma<N, N$ the buoyancy frequency) resembles internal wave theory (for $N>>f$ ). In winter, however, no significant near-inertial (or any other) spectral peak is observed and motions are not polarized at any frequencies, whatever the observation depths. With respect to the energy levels observed in summer, those in winter are enhanced at all frequencies (except near $f$ ). The seasonal pycnocline determines the summertime development of near-inertial and higher frequency internal waves, also at great depths ( 1100 $\mathrm{m}$ at least). In winter, no near-surface pycnocline does exist and no (gravity nor gyroscopic) near-inertial internal waves occur; the observed currents are associated with strong mesoscale activity and dense water formation, not with local $N$. For the 'internal wave band' this implies a lack of scaling of horizontal kinetic energy with $N$ that is reflected in changes of the spectral slope. In the coastal zone of the Ligurian Basin, especially near Corsica, where the alongslope circulation and an almost permanent stratification prevail, near-inertial currents are found yearlong, with only moderate changes in amplitude in the near-surface layer.
\end{abstract}

(c) 2003 Éditions scientifiques et médicales Elsevier SAS and Ifremer/CNRS/IRD. All rights reserved.

\section{Résumé}

Dans la partie centrale du bassin ligure (Méditerranée occidentale), un processus de formation d'eau dense se développe en hiver de sorte que la stratification des couches superficielles présente une variabilité saisonnière marquée. En conséquence, les spectres d'énergie cinétique depuis la surface jusqu'à des profondeurs intermédiaires sont très différents entre l'été et l'hiver. En été, les spectres montrent un pic près de la fréquence d'inertie locale $(f)$. La polarisation des courants dans la bande de fréquences $(\sigma)$ des ondes internes de gravité $(f<\sigma<N$, $N$ étant la fréquence de stabilité) suit la théorie (des ondes internes pour $N>>f$ ). En hiver cependant, aucun pic significatif n'apparaît, tant à la fréquence d'inertie qu'à toute autre fréquence, et les courants ne sont polarisés à aucune fréquence, quelle que soit la profondeur d'observation. Par rapport aux niveaux d'énergie observés en été, les niveaux en hiver sont plus importants à toutes les fréquences (sauf $f$ ). La pycnocline saisonnière détermine le développement estival d'ondes internes à la fréquence d'inertie et à des fréquences supérieures, jusqu'à des profondeurs relativement grandes ( $1100 \mathrm{~m}$ au moins). En hiver, aucune pycnocline superficielle n'existe et aucune oscillation d'inertie (de gravité ou gyroscopique) n'apparaît ; les courants observés sont associés à une forte activité de moyenne échelle et au processus de formation d'eau dense, pas à $N$. Ceci implique une absence de relation entre l'énergie cinétique horizontale et $N$ qui se traduit par des changements de la pente des spectres d'énergie dans la bande des ondes internes. Dans les zones côtières du bassin ligure, plus particulièrement près de la Corse,

\footnotetext{
* Corresponding author.

E-mail address: hansvh@nioz.nl (H. van Haren).
} 
là où la circulation le long de la pente et une stratification quasi-permanente prévalent, des oscillations d'inertie se développent de manière identique tout au long de l'année dans les couches superficielles.

(c) 2003 Éditions scientifiques et médicales Elsevier SAS and Ifremer/CNRS/IRD. All rights reserved.

Keywords: Seasonality; Internal gravity wave; Kinetic energy spectra; Ligurian Sea

Mots clés : Variations saisonnières ; Ondes internes de gravité ; Spectres d'énergie cinétique ; Mer Ligure

\section{Introduction}

Near-inertial currents oscillating periodically at frequencies $(\sigma)$ close to the local inertial frequency $f=2 \Omega \sin \phi(\phi$ denoting the latitude and $\Omega$ the Earth's rotational vector) dominate motions in the Mediterranean Sea, also at great depths. Although it is well accepted that near-inertial motions are mainly generated near the surface by atmospheric disturbances (e.g. Pollard and Millard, 1970; Millot and Crépon, 1981), uncertainties exist on the precise mechanisms for transporting near-inertial energy to great depths. Here, we study yearlong current meter observations down to $1100 \mathrm{~m}$ from the Ligurian Basin (Fig. 1), where (near-surface) stratification (Figs. 2 and 3b, d, f) and sub-inertial motions (Fig. 3a, c, e) vary strongly with the seasons, especially in the central part. It will be demonstrated that such seasonal variations affect near-inertial and higher frequency internal wave motions, near the surface and at intermediate depths too.

In the Mediterranean Sea, evaporation exceeds precipitation and river runoff. This leads to a water deficit that is compensated by an inflow of Atlantic water through the Strait of Gibraltar. Although Atlantic water is continuously transformed during its course anywhere in the Mediterranean, it

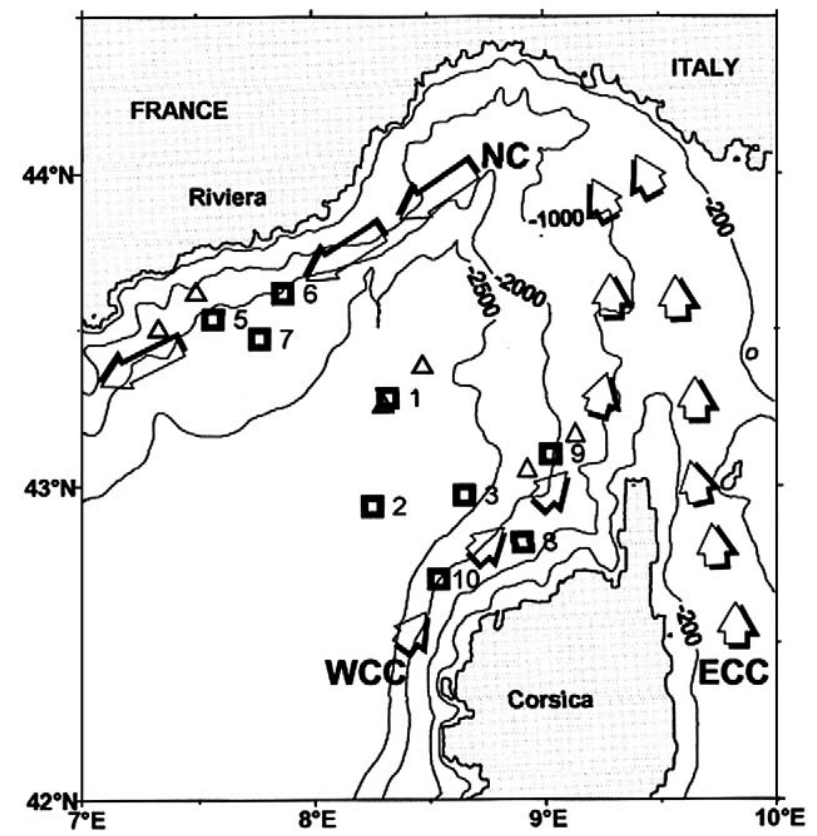

Fig. 1. Site of moorings (Y, numbered 1-10, 4 missing) during project 'DYOME'. CTD stations are indicated by ' $\Delta$ '. Arrows indicate the mean circulation. encounters major transformations in winter, due to cold and dry air masses that are entrained by violent northwesterly/north-easterly winds. The increase in density, which is linked yearlong to the increase in salinity, is so large in winter mainly due to cooling that superficial waters sink in some specific places. As a result, Atlantic water is continuously transformed into a saltier and cooler Mediterranean water that can be recognized in the entire northern Atlantic ocean after its outflow out of the Mediterranean. In the Western Mediterranean Sea, most of the dense water is formed in the Gulf of Lions (offshore between the Pyrenees and the Rhone outflow) where meteorological conditions are extremely severe, but dense water can also be formed in the neighboring Ligurian Basin.

Therefore, after its inflow through the Strait of Gibraltar part of the Atlantic water must flow northwards (whilst the rest flows towards the Eastern Mediterranean Sea). This occurs due to two different processes and thus along two different routes (Millot, 1999). One process, a geostrophic adjustment process first described by Crépon et al. (1989), governs an anticlockwise rim current surrounding the dense water formation zone. When winds are blowing from the north over a "Mediterranean Sea", the zone of dense water formation tends to reach the northern coasts, so that the rim current is constrained there, whilst more spread in the south. A Northern Current (NC) thus develops alongslope in the northern parts of all "Mediterranean Seas" (Millot, 1992). In the Western Mediterranean Sea it can be clearly identified from Sicily to the Italian peninsula: in the Corsica channel between Corsica and Italy (it is usually named Eastern Corsica Current, ECC, there), the French Riviera, in the Gulf of Lions, in the Balearic Basin and finally through the Ibiza channel. Another process, first described by Millot (1985), is related to mesoscale eddies generated by the marked unstability of the Algerian Current, which entrains a northward spreading of Atlantic water that will finally flow alongslope west of Corsica. In the Ligurian Basin, the Western Corsica Current (WCC) joins the ECC to form the NC (Fig. 1).

The major point to keep in mind is that the two coastal zones covered by our mooring array are thus concerned with alongslope currents (the WCC in the south and the NC in the north) that are driven by different processes and thus display different characteristics (Millot, 1991). The WCC displays a mesoscale variability that is roughly similar yearlong while the $\mathrm{NC}$ is faster, thinner, deeper and more unstable in winter than in summer (Albérola et al., 1995a). During winter, the NC generates an intense mesoscale activity that spreads 

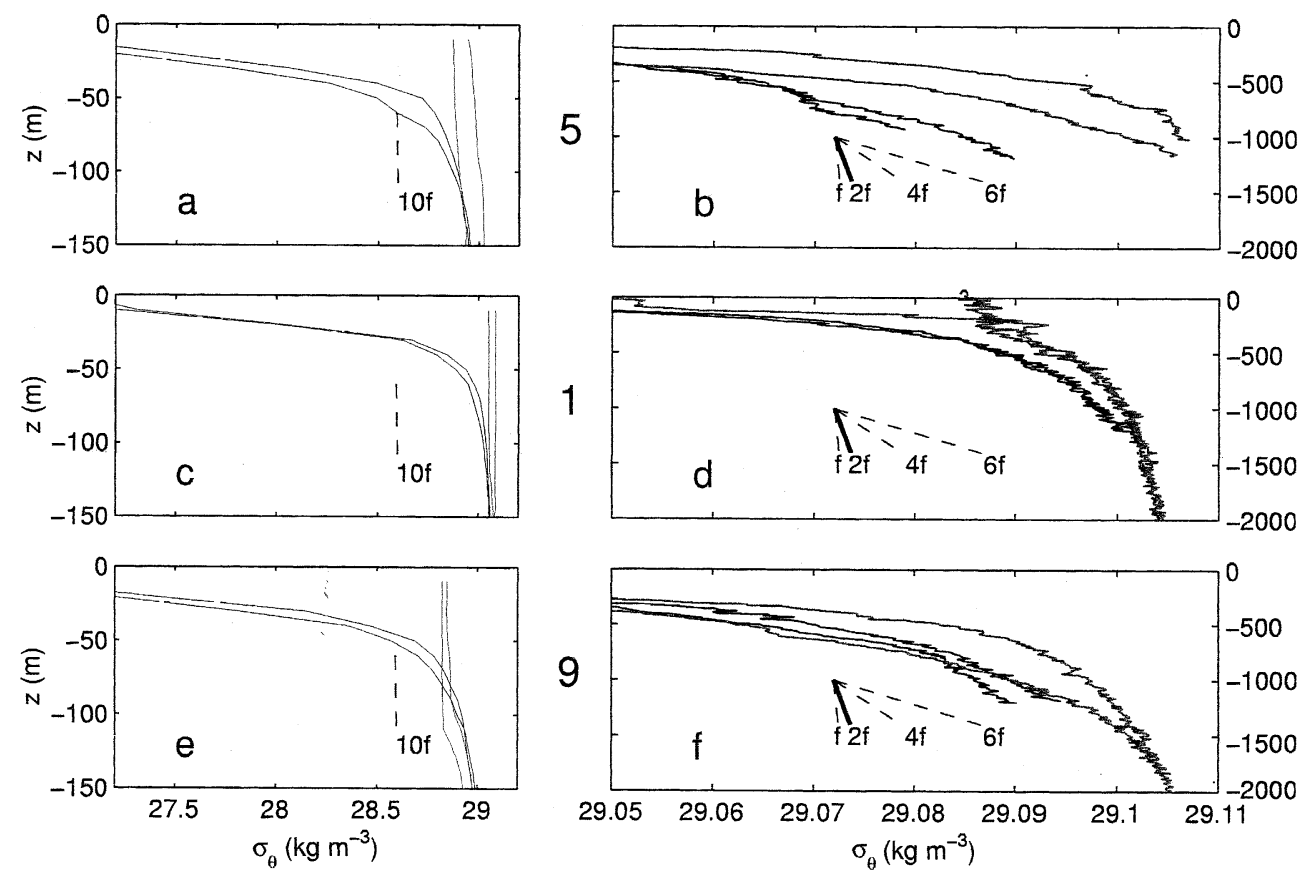

Fig. 2. Examples of potential density-depth profiles from CTD in the abyssal Ligurian Basin. Summer profiles (July campaign, cast maximum depth 1150 m) are in black, winter profiles (February, 1982) in blue. (a) Northern Ligurian Sea (near the continent and mooring 5), upper layer. (b) Detail of profile in (a) at greater depths. The short sloping lines indicate density stratification yielding $N=f, 4 f, 6 f, 10 f$ (dashed lines) and $N=2 f$ (heavy solid line). Potential density is referenced to $z=0$ in (a) and to $z=-1100 \mathrm{~m}$ in (b). (c and d) As (a and b), but for the central Ligurian Sea (mooring 1). (e and f) As (a and b), but for the southern Ligurian Sea (near Corsica, mooring 9).

seawards, from the Riviera coastal zone across the central Ligurian Basin up to the Corsica coastal zone (TaupierLetage and Millot, 1986; Millot, 1987). In the neighboring Gulf of Lions, wintertime vertical kinetic energy is 100 times larger than in summer, whilst stratification is less by only a factor of $\sim 1.5$ at $750 \mathrm{~m}$ (Gascard, 1975). Such seasonal variations are reflected in the horizontal current kinetic energy (Gonella, 1971; Gascard, 1973), but not everywhere in the same way as will be demonstrated here.

We consider spectra from three moorings (1, 5 and 9; Fig. 1) that are representative of the three major zones of the Ligurian Basin, and thus display a sharp contrast in mesoscale activity and stratification. Mooring 1 (as moorings 2, 3 and also 7) is representative of the central zone where wintertime dense water formation generally occurs. Mooring 5 (as mooring 6) is representative of the Riviera zone and of the seasonal variability associated with the NC. Mooring 9 (as moorings 8 and 10) is representative of the Corsica zone and of the yearlong variability associated with the WCC. Although stratification displays everywhere some seasonal variability, this variability is relatively moderate off Corsica and dramatic in the central zone. Across the basin, the atmospheric forcing is different too with respect to northerly (lato sensu) winds. Although the winds most efficient for dense water formation are associated with large intense meteorological events and thus blow over the whole domain, they often blow from the west/south-west in the south, where intense gusts are also encountered in summer, and from the east/north-east in the north. We will show that this results in different spectral properties at the different moorings.

\section{Data handling}

Between July 1981 and July 1982, Aanderaa RCM-5 current meter data were obtained from nine moorings in the Ligurian Sea (Fig. 1; mooring 4 was not recovered) during project 'Dyome' (Taupier-Letage and Millot, 1986). Although the moorings consisted of three to five current meters, we considered data from common depths at 100, 350 and $1100 \mathrm{~m}$, all well above the bottom $(H \sim 2600 \mathrm{~m}$ water depth at mooring 1; $H \sim 2000 \mathrm{~m}$ at moorings 5 and 9). The current meter at $100 \mathrm{~m}$ at mooring 9 returned only 180 days of (summer-autumn) data. As a replacement, data from $100 \mathrm{~m}$ at mooring 8 were used. The current meters sampled once per hour, so that all phenomena of major importance here (up to frequencies $\sigma<10 f$ ) are well resolved.

Since the data presented here were from non-vector averaging mechanical current meters in areas where current speeds were occasionally low, contamination was anticipated. The summertime data from $1100 \mathrm{~m}$ evidenced a stalled rotor up to $50 \%$ of the measurements due to low current speeds. This did not affect our general conclusions, and it determined in part the criterion for selecting time series sub-sections to be analyzed. An obvious important part of this criterion was the existence of near-surface stratification or vertical homogenization, during a consecutive period of time equal for most locations and for both seasons. Thus, two 100-day time series sub-sections (Fig. 3) were spectrally analyzed.

We performed rotary $\left(P_{+}, P_{-}\right)$and kinetic energy $\left(P_{\mathrm{KE}}=P_{+}+P_{-}\right)$spectral analyses. For the rotary spectra we 

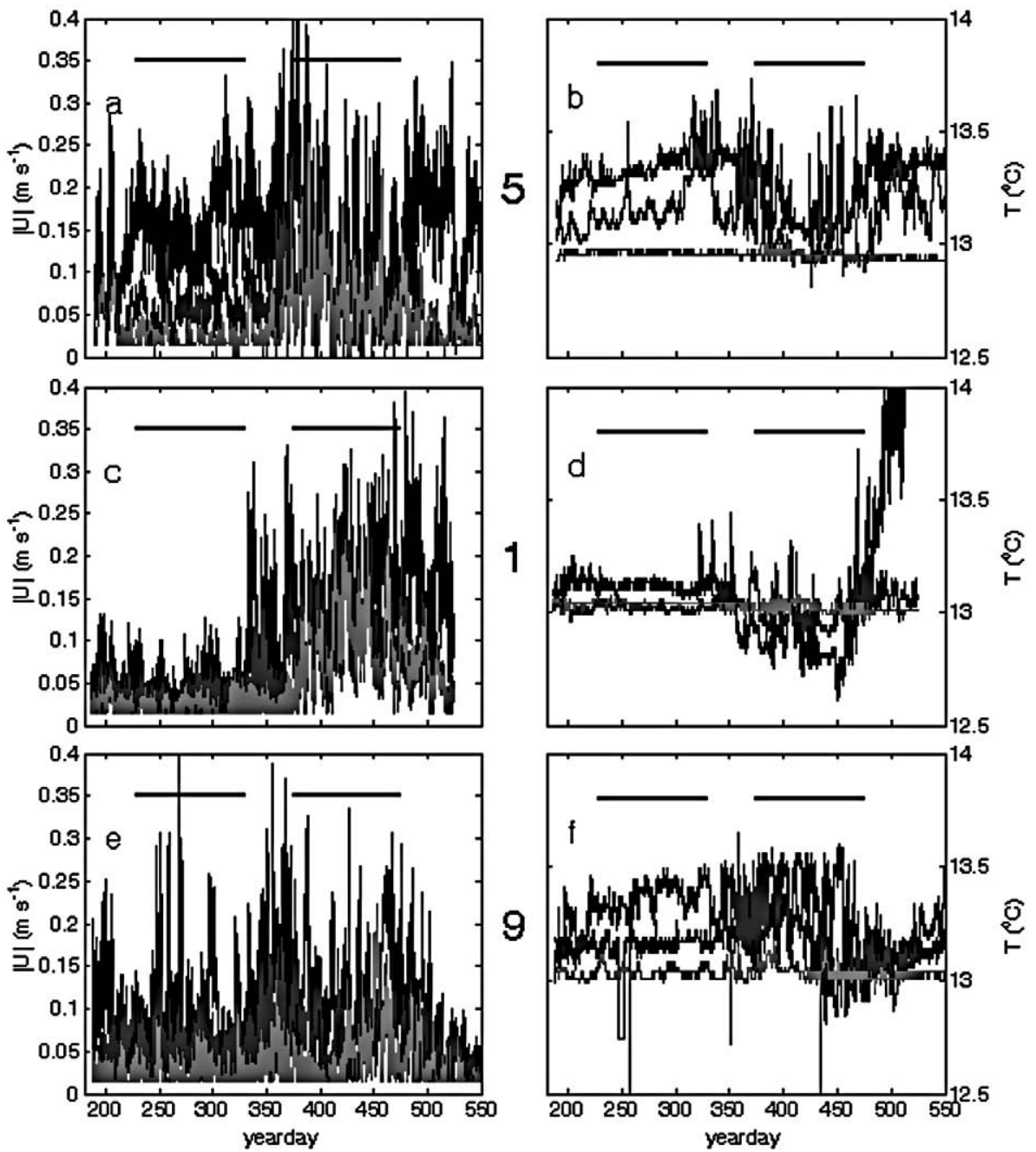

Fig. 3. (a) Time series of current speed for three depths at mooring 5, $100 \mathrm{~m}$ (black), $350 \mathrm{~m}$ (blue) and $1100 \mathrm{~m}$ (red). The horizontal bars show the time series sub-sections used in the spectral analysis. (b) As (a) but for temperature. (c and d) As (a and b), but for mooring 1. (e and f) As (a and b), but for mooring 9 $(350$ and $1100 \mathrm{~m})$ and $8(100 \mathrm{~m})$.

used the method by Gonella (1972). Using rotary power spectra $P_{-}(\sigma)$ for the clockwise component and $P_{+}(\sigma)$ for the anti-clockwise component, the polarization of the ellipses was inferred from the 'rotary coefficient',

$$
\mathrm{C}_{\mathrm{R}}(\sigma)=\left|\mathrm{P}_{-}(\sigma)-\mathrm{P}_{+}(\sigma)\right| / \mathrm{P}_{\mathrm{KE}}(\sigma)
$$

$C_{\mathrm{R}}(\sigma)=0$ for pure rectilinear motion at frequency $\sigma$ and 1 for pure circular motion. Under linear, symmetric forcing, for example generating linear internal gravity waves, a simple expression is found (for buoyancy frequency $N=(-g$ $\mathrm{d} \ln \rho / \mathrm{d} z)^{0.5}>>f$ ),

$$
\mathrm{C}_{\mathrm{R}}(\sigma)=\frac{2 \sigma \mathrm{f}}{\sigma^{2}+\mathrm{f}^{2}}
$$

$C_{\mathrm{R}}$ can also be used to discriminate between internal gravity waves and internal inertio (gyroscopic) waves (van Haren and Millot, 2003). The latter have $C_{\mathrm{R}}=1$ for all frequencies in a plane perpendicular to their wavenumber vector (LeBlond and Mysak, 1978). However, as the angle between this vector and the vertical is non-zero except at the poles, horizontal gyroscopic near-inertial wave motions show a non-circular polarization due to projection of their tilted circular hodographs on the horizontal plane. Such waves still exist between frequencies $0<\sigma<2 \Omega$ in case the buoyancy frequency $N=0$, as in wintertime near the surface, and internal gravity waves vanish. For $N>>2 \Omega$ free internal gravity waves exist in the familiar frequency band $f<\sigma<N$. For weak stratification $(N=O(f))$, as is found in deeper parts of the Mediterranean Sea, inertio-gravity waves exist between $\sigma_{\text {low }}<f<\sigma<N<\sigma_{\text {high }}$, with the low and high limits depending on $N / \Omega$ as given explicitly by several authors (Saint-Guily, 1970; Gascard, 1973; LeBlond and Mysak, 1978). For example, for $N=3 f \approx 4 \Omega$ (1100 $\mathrm{m}$ at mooring 1 in summer) we find an internal wave band $\sigma_{\text {low }}=0.92 f<\sigma<1.1 N=\sigma_{\text {high }}$.

Variations in stratification also determine the energy level of internal gravity waves. Following Garrett and Munk (1972) (henceforth GM) the kinetic energy power level $P_{\mathrm{KE}}(\sigma) \sim N \sigma^{p},-2.5<p<-1.5$, for $f<<\sigma<<N$. As a result, we expect no kinetic energy scaling with $N$ when conditions are favorable for pure gyroscopic waves $(N=0)$. 

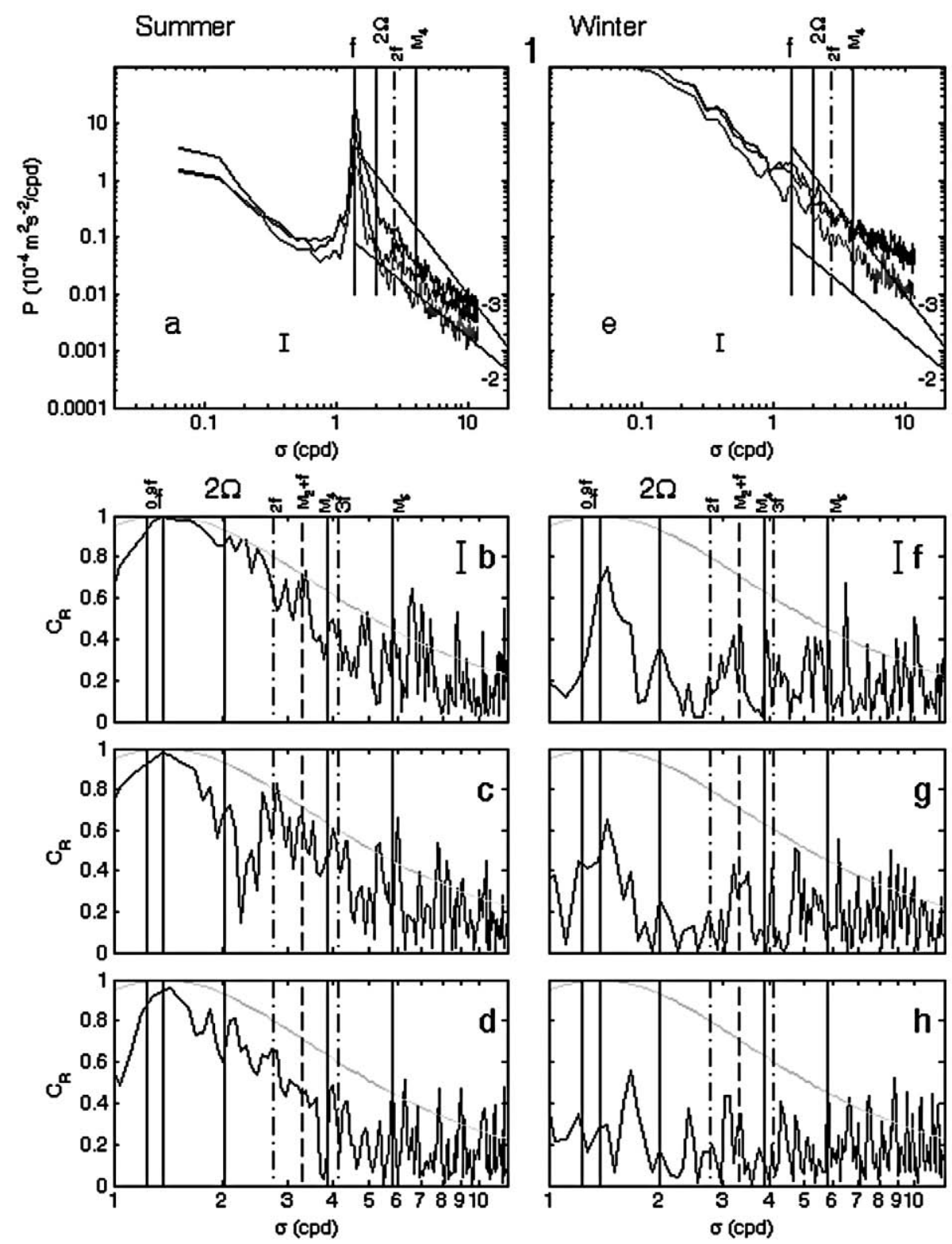

Fig. 4. Spectral observations for mooring 1 ("central Ligurian Basin”). (a) 'Summer' kinetic energy spectra from 3 months (10 August-15 November 1981 ) of current meter observations at $100 \mathrm{~m}$ (black), $350 \mathrm{~m}$ (blue), $1100 \mathrm{~m}$ (red). The $95 \%$ significance confidence interval is indicated by the vertical bar. For $\sigma>f$ two reference spectral slopes are indicated, a constant sloping $P(\sigma) \propto \sigma^{-3}$ (indicated by ' -3 ') and $P(\sigma) \propto \sigma^{-2}$ (' -2 '). (b) $C_{\mathrm{R}}(\sigma)$ from $(1)$ for $100 \mathrm{~m}$ during the same period as in (a). The smoothly sloping green line indicates theory (2). (c) As (b) but for $350 \mathrm{~m}$. (d) As (b) but for $1100 \mathrm{~m}$. (e-g) As (a-d) but for the 'winter' period (2 January-10 April 1982).

\section{Observations}

The seasonal variation in near-surface stratification (Fig. 2a, c, e) and mesoscale activity (Fig. 3a, c, e) affected the horizontal current spectra at all depths throughout the Ligurian Basin (Figs. 4-6). Less stratification below 100 m (Fig. 2d) and larger seasonal differences in mesoscale activity (Fig. 3c) in the center of the basin affected details in the observed spectra with respect to those from sites close to the coasts (Figs. 2b, f and 3b, f).

In summer, when a pycnocline was near 20-50 m depth and when mesoscale activity was relatively low, kinetic energy spectra in all three zones (Figs. 4a, 5a and 6a) showed a strong inertial peak at frequency $\sigma_{p}=1.02 \pm 0.02 f$ independent of depth. Also a (barely significant) peak was observed at $2 f$ at deeper levels mainly in the center of the basin (Fig. 4a). These peaks extended above an otherwise featureless sloping continuum in the internal wave band. At mooring $1, N(100) \approx 10 f$, whilst $N(350) \approx 6 f$ and $N(1100) \approx 3 f$ (Fig. 2 ). Thus, the internal gravity wave band was just resolved by the hourly sampling for all observational depths. This observed variation of stratification with depth reflected the change with depth of kinetic energy level between $f \leq \sigma<3 f$ (Fig. 4a). Along the basin's edges at moorings 5 (Fig. 5a) and 9 (Fig. 6a), the energy level at $100 \mathrm{~m}$ relative to 350 and $1100 \mathrm{~m}$ 

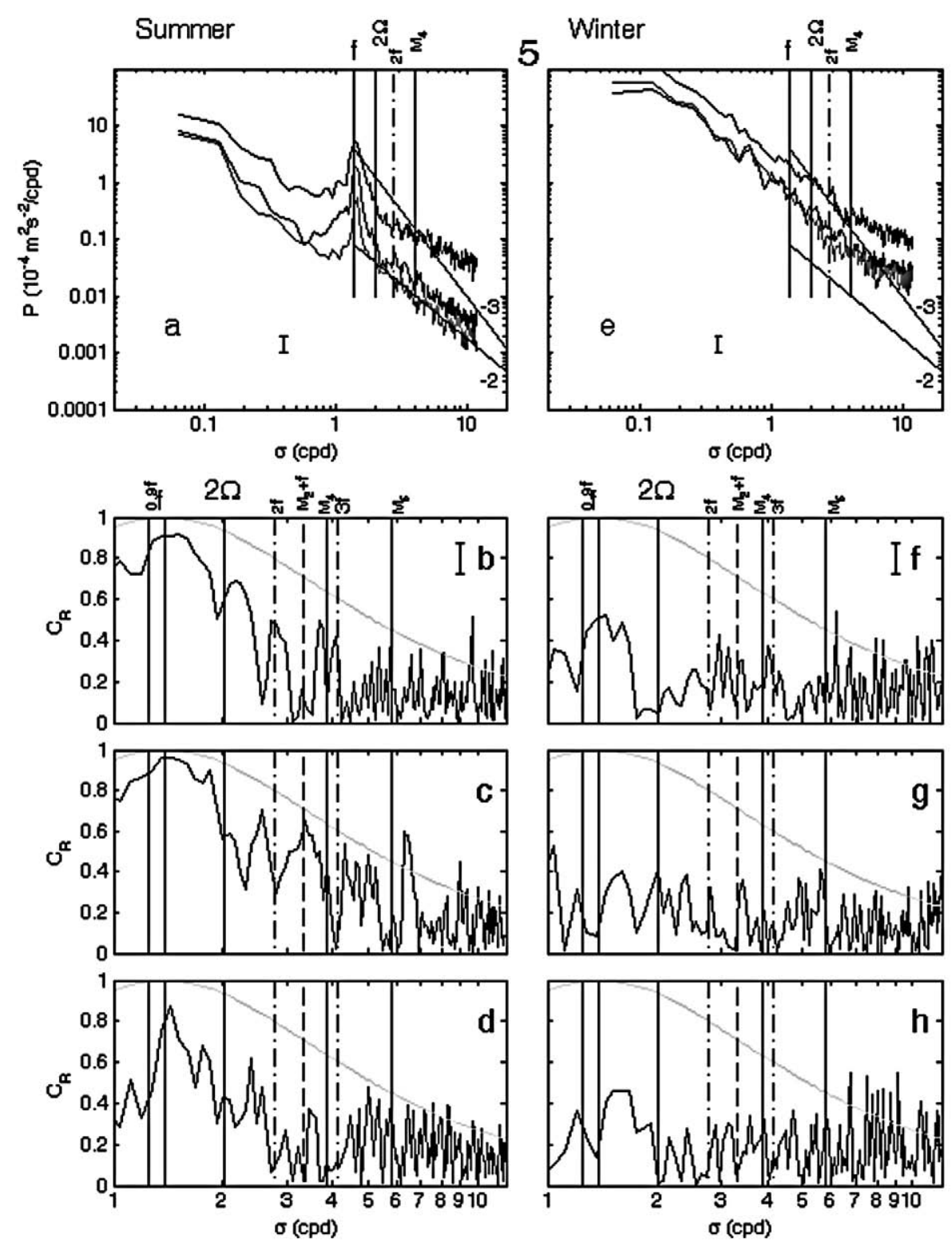

Fig. 5. As Fig. 4 but for mooring 5 ("northern Ligurian Basin").

was much larger than predicted by GM, also because the deeper stratification was about twice the value that was observed in the center of the basin $(N(1100) \approx 6 f$, Fig. 2 d). With sub-inertial energy near the edges being larger than in the center of the basin, high frequency internal wave band $(\sigma>4 \mathrm{cpd})$ kinetic energy was larger at moorings 5 and 9 than at mooring 1, albeit less than by a factor of 2 (the observed ratio in $N$ ) at $1100 \mathrm{~m}$. In contrast, near-inertial energy levels increased monotonically from the continent towards Corsica, at all depths except $350 \mathrm{~m}$ (showing a maximum at mooring 1).

At the three moorings, the spectral continuum for $1.4 f<\sigma<3 f$ outside the near-inertial band showed a varying slope with mean $p=-2.1 \pm 0.6$ (Table 1$)$. A slope of $p=-$ 3 was suggested as evidence of internal wave motions following non-linear interactions (van Haren et al., 2002). Such slope was found only near the surface in the center of the basin, but a weak peak near $2 f$ may have obscured the background spectral slope in this rather small internal gravity wave frequency band.

Supporting evidence of summertime internal gravity waves was obtained from inspection of rotary coefficient spectra (Figs. 4b-d, 5b-d and 6b-d). At mooring 1 at 100 and $350 \mathrm{~m}$, good correspondence was found between (internal wave) theory (2) and the observations for $f<\sigma<3 f$. In the same frequency band, such correspondence was less at $1100 \mathrm{~m}$ and near the edges of the basin at all depths, with poorest correspondence at mooring $5,1100 \mathrm{~m}$. The weaker correspondence at greater depths was only weakly attributable to weaker $N$, as $N(1100)$ resulted in a shift of the lower bound of the internal wave band to $\sigma_{\text {low }}=0.92 f$ implying $3 \%$ less polarization at $1.02 f$. Not surprisingly, we did not observe a significant shift in frequency of the internal wave band peak for different $N(z)$ in summertime spectra. 

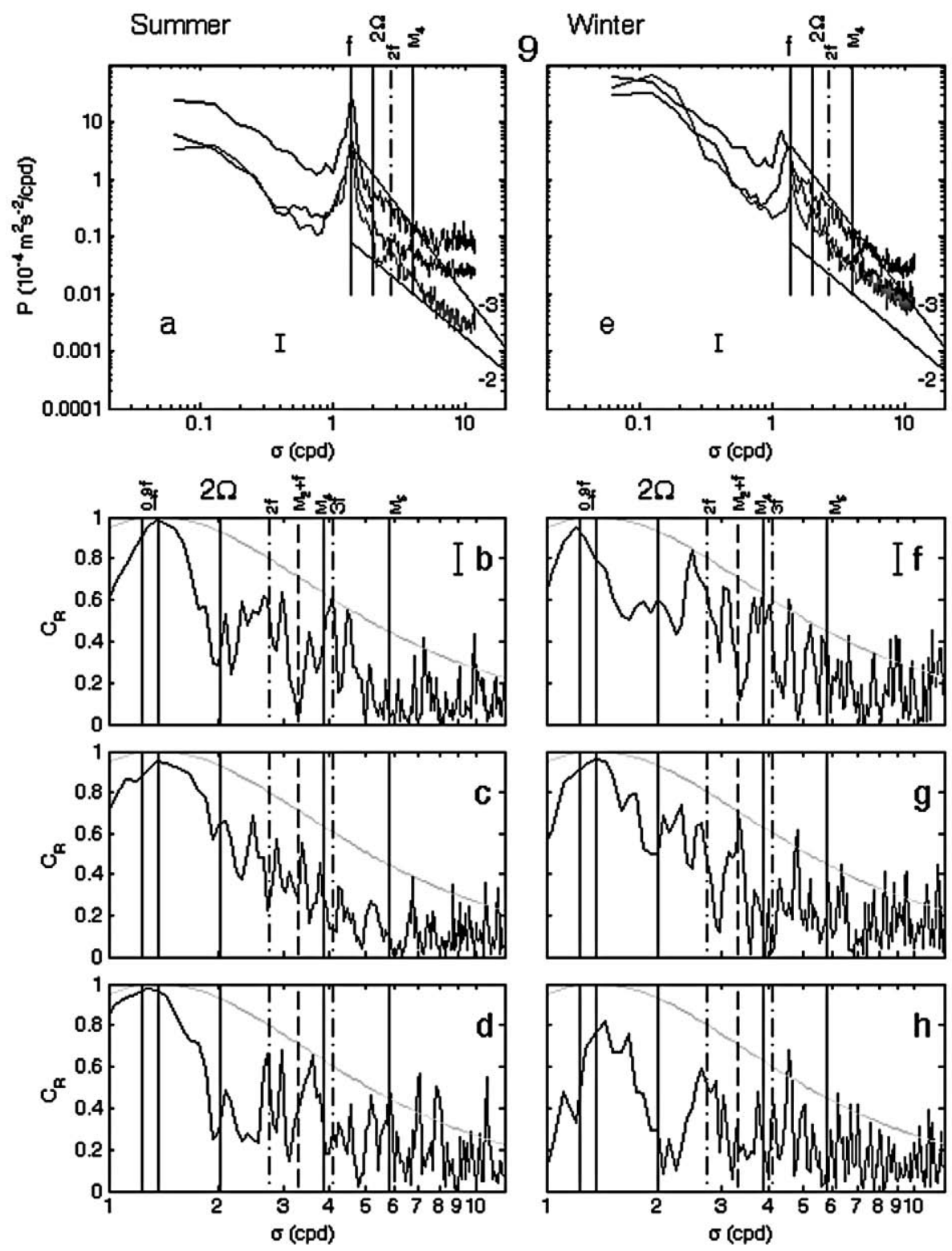

Fig. 6. As Fig. 4 but for mooring 9 ("southern Ligurian Basin"), except for the black spectrum in (e) and $C_{\mathrm{R}}$ in panel (f) (both mooring 8, $100 \mathrm{~m}$ ).

In winter, the kinetic energy spectra were flat and featureless at moorings 1 and 5 (Figs. 4e and 5e) but peaks were still observed at mooring 9 (Fig. 6e). The spectra were about 10 times more energetic at all moorings at all depths than in summer (except at mooring 9, $100 \mathrm{~m}$ where the spectrum was only a few times larger). This was observed at all frequencies up to $\sigma \sim 3 f$ (except $f$ ), whilst stratification changed barely with the seasons below $350 \mathrm{~m}$ (and below $150 \mathrm{~m}$ at point 9)
(Fig. 2). A significant aspect of moorings 8-10, for $\sigma>3 f$ at 100 and $350 \mathrm{~m}$ mainly, was energy due to noise being larger in summer than in winter. This was probably due to (i) the frequent occurrence of gusts of south-westerly winds in the southern Ligurian Basin during summer (at moorings 9 and 1 but not 5) and (ii) to the stratification on the edges of the Ligurian Basin (at moorings 9 and 5) that was larger than in the center (mooring 1). Therefore, both conditions for year-

Table 1

Least-square fit of spectral slope $p$ for $1.4 f<\sigma<3 f$, part of the internal wave band excluding motions at $f$, computed for moderately smoothed spectra $(v \approx 20 \mathrm{df}$; degrees of freedom) for the different moorings and seasons. One standard deviation equals 0.3 , for each slope.

\begin{tabular}{llllll}
\hline$z(\mathrm{~m})$ & Mooring & & & & \\
& 1 (summer) & 1 (winter) & 5 (summer) & 5 (winter) & $9($ summer) \\
\hline-100 & -3.4 & -2.2 & -1.6 & -2.3 & -2.0 \\
-350 & -1.7 & -1.7 & -1.8 & -2.2 & -2.6 \\
-1100 & -2.5 & -2.3 & -2.2 & -1.9 & -3.9 \\
\hline
\end{tabular}


long downward propagation of internal waves (i.e. energy input and stratification near the surface) were satisfied only in the Corsica coastal zone.

The wintertime spectral slopes were more or less continuous across all frequencies at all depths, albeit values varied per mooring with a mean of $p=-2.3 \pm 0.4$ (Table 1 ). This mean slope was not significantly different from the summertime mean slope (given above). However, in winter, except at mooring 9, this mean slope did not reflect internal gravity waves following GM. Instead it reflected abrupt current changes passing our instruments: "fine-structure contamination", which exhibits a theoretical spectral slope of $p=-2$ (Phillips, 1971; Reid, 1971; Garrett and Munk, 1971). Here, this slope was evidence of intense mesoscale activity up to about $5 \mathrm{cpd}$.

The lack of internal gravity waves in our wintertime observations at moorings 1 and 5 was confirmed after inspection of the rotary coefficient spectra (Figs. 4f-h and $5 \mathrm{f}-\mathrm{h}$ ). Horizontal currents were less polarized than theory (2) at all internal wave band frequencies and at all depths, compared to summertime data. This seasonal contrast in $C_{\mathrm{R}}$ was greatest close to the continent (mooring 5; Fig. 5) and we noted its gradual diminution across the basin. At mooring 1 (Fig. 4e-h) a weak, non-significant, near-inertial enhancement was observed in winter. At mooring 9 (Fig. 6e-h) wintertime spectra showed only marginally less internal gravity wave properties than in summer. At this mooring we observed a significant wintertime near-inertial peak, albeit weaker at 100 and $1100 \mathrm{~m}$ than in summer. We also observed a vertical change of the wintertime near-inertial peak frequency from $0.9 f$, via $1.02 f$, to $1.05 f$ at 100,350 and $1100 \mathrm{~m}$, respectively. The change in peak frequency and in peak height at $100 \mathrm{~m}$ was attributed to a change in stratification. The almost unchanged near-inertial and internal wave band spectra at $350 \mathrm{~m}$ confirmed the observed stratification at this depth (Fig. 2), being almost constant yearlong. Apparently, this was not (always) the case at moorings 1 and 5, probably due to a stratification that reduced markedly (at mooring 5) and dramatically (at point 1), following episodes of dense water formation not captured by our CTD observations. The (weak) seasonal differences in near-inertial and internal wave properties at $1100 \mathrm{~m}$ at mooring 9 suggested mesoscale turbulence generated in the Riviera coastal zone occasionally propagating toward the Corsica coastal zone and finally reaching it in late winter (Taupier-Letage and Millot, 1986).

\section{Discussion}

The observed seasonal differences of near-inertial and higher frequency internal wave motions in the Ligurian Basin is similar to observations in the seasonally stratified North Sea (van Haren, 2000, 2003). Absence of near-inertial motions in the North Sea in winter is attributed to a lack of support of inertial shear by stratification, whilst the shallow depths also prevent the development of strong inertial currents due to mixing induced by bottom friction and coastal effects (Davies, 1985a, b, 1986). In the Ligurian Basin, wintertime mixing due to convective overturning destroys the seasonal pycnocline and at least weakens (if not suppressing) stratification below $500 \mathrm{~m}$ depth in the central part of the basin (Fig. 2d; Gascard, 1975). Stratification is not modified below 100-200 $\mathrm{m}$ in the southern part mainly.

Certainly, the wintertime destruction of the seasonal pycnocline prevents (slab-layer) generation of strong nearsurface near-inertial motions (e.g. Pollard and Millard, 1970) and, thereby, near-inertial motions below the pycnocline. Apparently, this also prevents generation of pure gyroscopic internal waves, even in the near-surface layer where $N \sim 0$, in the Ligurian Basin. Such waves were observed in the Algerian Basin (van Haren and Millot, 2003). Wintertime homogenization in a dense water formation zone is associated with intense mesoscale activity that perhaps hides or destroys gyroscopic-gravity waves that are free to develop in the quieter Algerian Basin.

This lack of deep near-inertial internal wave motions also affects higher frequency internal wave motions and spectral slopes at intermediate depths, as evidenced from the seasonal differences in rotary spectral properties. In both the deep Ligurian Basin and the shallow North Sea, lack of nearinertial vertical current shear (due to lack of horizontal nearinertial motions) is accompanied by an absence of internal gravity waves in general. This seasonal difference in spectral slopes is best presented in a comparison of internal wave band slopes from summertime rotary spectra referenced to wintertime kinetic energy spectra (Fig. 7). For $1.4 f<\sigma<3 f$ the summertime $P_{-}(\sigma)$ spectrum slope $p \approx-3.3 \pm 0.3$, whilst the $P_{+}(\sigma)$ spectrum shows $p \approx-1.0 \pm 0.3$. The significant difference in slopes between the summertime rotary components and between summer and winter internal wave band spectra clearly shows that spectral (GM) scaling with stratification does not always apply. Comparing at a particular depth below the pycnocline the kinetic energy spectra from the two seasons, when there is a marked seasonality, the observed spectral level is larger by a factor of $\sim 10$ for all internal wave and sub-inertial frequencies (except $f$ ) in winter, whilst mean $N$ is nearly unchanged. One needs to consider the slope of power spectra, rotary spectra and the persistency of $N(z)$ with time too, to establish the importance

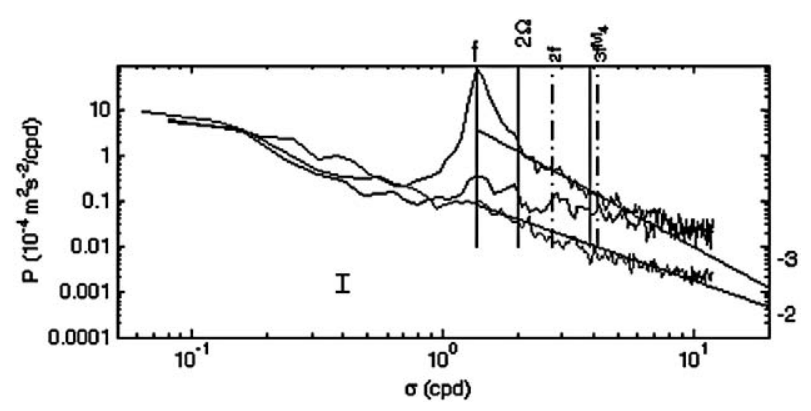

Fig. 7. Spectral slopes for summertime rotary spectra from mooring 1, $100 \mathrm{~m}$ (clockwise in blue, anticlockwise in black) referenced to the wintertime (total) kinetic energy spectrum (in red; offset by 1.5 decades for clarity and for reference with the -2 sloping line). 
of internal gravity waves relative to undetermined 'finestructure contamination noise' due to abrupt changes (in temperature or current) passing the moored sensors.

Using the above information for distinguishing internal gravity waves from noise contamination proves the yearlong persistence of internal waves at mooring 9, $350 \mathrm{~m}$ and, to a lesser degree, at 100 and $1100 \mathrm{~m}$. Closer to the surface there are occasional interactions with the atmosphere and deeper there might be the spreading of dense water formed in the central zone, causing (weak) variations in stratification. However, at $350 \mathrm{~m}$ at point 9 "new" Levantine Intermediate Water and, at greater depths, Tyrrhenian Sea Deep Water, are continuously filling the Ligurian Basin (Millot, 1999) so that stratification will never vanish. As in the summer observations, the springtime and, at mooring 9, the wintertime, near-inertial peak at $350 \mathrm{~m}$ was centered at $1.02 f$, irrespective the strength of the (near-surface) stratification.

\section{Conclusions}

The central Ligurian Basin is very weakly $(N \sim O(f))$ stratified down to great depths in winter, due to dense water formation. In the absence of measurable tides $\left(<10^{-3} \mathrm{~m}\right.$ $\mathrm{s}^{-1}$ Albérola et al., 1995b), this weak stratification affects the presence of oscillatory (internal wave) motions and associated shear. Only in summer when a slab-layer exists above a strong near-surface pycnocline, stratification is sufficiently large to support internal waves below this pycnocline, and nearly circular near-inertial horizontal motions dominate at all intermediate depths. The near-inertial motions have a peak frequency of $1.02 f$, which resembles a resonance frequency, independent of the frequency bounds of free inertiogravity waves (due to varying $N$ ). We conclude that the above sketched initial near-surface stratification and generation of near-inertial motions also affects the fate of the latter in the entire water column. With the dominance of near-inertial motions other internal waves are supported, because $N>f$. In winter, stratification is not observed significantly different from summertime observations, except in the upper 2-300 m where a pycnocline no longer exists. However, it is noted that our CTD-observations may have missed short-lived moments of deep convection. With the lack of a near-surface pycnocline no internal waves and no dominant frequency band (for either internal gravity or gyroscopic waves) are observed, whilst kinetic energy is 10 times larger than in summer. With the stronger sub-inertial motions associated with mesoscale activity, energy levels at all frequencies are enhanced. The kinetic energy spectrum slopes like $\sigma^{-2}$ across all frequencies, also well below internal gravity wave frequencies. The above conclusions are for the central Ligurian Basin, whilst different spectral properties are observed along the edges, summarized in Fig. 8.

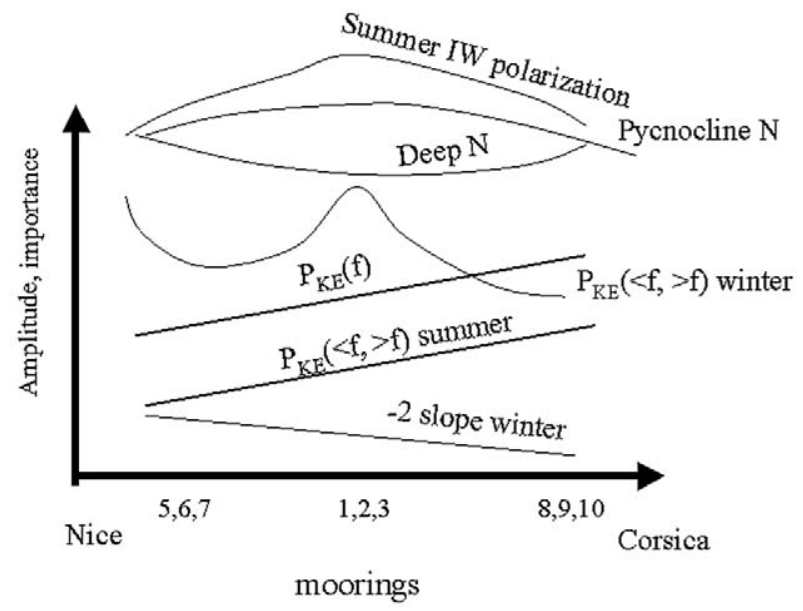

Fig. 8. Impression of the variation of several quantities across the Ligurian Sea.

\section{Acknowledgements}

We thank the crews of R.V. "Le Noroit" and "CatherineLaurence", as well as both CNRS and Ifremer, that allowed collecting the data and recovering the moorings. Isabelle Taupier-Letage provided Fig. 1. HvH thanks Ifremer for the hospitality during his stay in La Seyne-sur-mer, which was generously supported by a grant from the Netherlands organization for the advancement of scientific research, NWO, in the French-Dutch exchange program.

\section{References}

Albérola, C. Millot, C. Font, J. 1995a. On the seasonal and mesoscale variabilities of the Northern Current during the PRIMO-0 experiment in the western Mediterranean Sea. Oceanol. Acta 18, 163-192.

Albérola, C. Rousseau, S. Millot, C. Astraldi, M. Font, J. Garcia-Lafuente, J. Gasparini, G.P. Send, U. Vangriesheim, A. 1995b. Tidal currents in the interior of the Western Mediterranean Sea. Oceanol. Acta 18, 273-284.

Crépon, M. Boukthir, M. Barnier, B. Aikman III, F. 1989. Horizontal ocean circulation forced by deep-water formation: part I. An analytical study. J. Phys. Oceanogr. 19, 1781-1792.

Davies, A.M. 1985a. Application of a sigma coordinate sea model to the calculation of wind-induced currents. Cont. Shelf Res. 4, 389-423.

Davies, A.M. 1985b. A three-dimensional modal model of wind induced flow in a sea region. Prog. Oceanogr. 15, 71-128.

Davies, A.M. 1986. Application of a spectral model to the calculation of wind drift currents in an idealized stratified sea. Cont. Shelf Res. 5, 579-610.

Garrett, C. Munk, W. 1971. Internal wave spectra in the presence of finestructure. J. Phys. Oceanogr. 1, 196-202.

Garrett, C.J.R. Munk, W.H. 1972. Space-time scales of internal waves. Geophys. Fluid Dyn. 3, 225-264.

Gascard, J.-C. 1973. Vertical motions in a region of deep water formation. Deep-Sea Res. 20, 1011-1027.

Gascard, J.-C. 1975. Comparaison des mouvements verticaux observés en profondeur en Méditerranée Nord-occidentale en régime d'été et en régime d'hiver. C. R. Acad. Sci. Paris 280, 555-558.

Gonella, J. 1971. A local study of inertial oscillations in the upper layers of the ocean. Deep-Sea Res. 18, 775-788.

Gonella, J. 1972. A rotary-component method for analysing meteorological and oceanographic vector time series. Deep-Sea Res. 19, 833-846. 
LeBlond, P.H. Mysak, L.A. 1978. Waves in the Ocean. Elsevier, Amsterdam. Millot, C. 1985. Some features of the Algerian Current. J. Geophys. Res. 90, 7169-7176.

Millot, C. 1987. The structure of mesoscale phenomena in the Ligurian Sea inferred from the DYOME experiment. Ann. Geophys. 5, 21-30.

Millot, C. 1991. Mesoscale and seasonal variabilities of the circulation in the western Mediterranean. Dyn. Atmos. Oceans 15, 179-214.

Millot, C. 1992. Are there major differences between the largest Mediterranean Seas? A preliminary investigation. Bull. Inst. Oceanogr. Monaco $11,3-25$.

Millot, C. 1999. Circulation in the Western Mediterranean Sea. J. Mar. Syst. 20, 423-442.

Millot, C. Crépon, M. 1981. Inertial oscillations on the continental shelf of the Gulf of Lions-observations and theory. J. Phys. Oceanogr. 11, 639-657.

Phillips, O.M. 1971. On spectra measured in an undulating layered medium. J. Phys. Oceanogr. 1, 1-6.

Pollard, R.T. Millard, R.C. 1970. Comparison between observed and simulated wind-generated inertial oscillations. Deep-Sea Res. 17, 813-821.
Reid, R.O. 1971. A special case of Phillips' general theory of sampling statistics for a layered medium. J. Phys. Oceanogr. 1, 61-62.

Saint-Guily, B. 1970. On internal waves, effects of the horizontal component of the Earth's rotation and of a uniform current. D. Hyd. Z. 23, 16-23.

Taupier-Letage, I. Millot, C. 1986. General hydrodynamic features in the Ligurian Sea inferred from the DYOME experiment. Oceanol. Acta 9, 119-132.

van Haren, H. 2000. Properties of vertical current shear across stratification in the North Sea. J. Mar. Res. 58, 465-491.

van Haren, H. 2003. Current spectra under varying stratification conditions in the central North Sea. J. Sea Res. (in press).

van Haren, H. Millot, C. 2003. Rectilinear and circular inertial motions in the Western Mediterranean Sea. Oceanol. Acta (accepted for publication).

van Haren, H. Maas, L. van Aken, H. 2002. On the nature of internal wave spectra near a continental slope. Geophys. Res. Lett. 29 (12) 10.1029/2001GL014341. 